\title{
Spinocerebellar Ataxia Type 3
}

National Cancer Institute

\section{Source}

National Cancer Institute. Spinocerebellar Ataxia Type 3. NCI Thesaurus. Code C84830.

A very rare, autosomal dominant inherited neurodeg enerative disorder. Signs and

symptoms include ataxia, spasticity, and abnormalities in the ocular movements. 